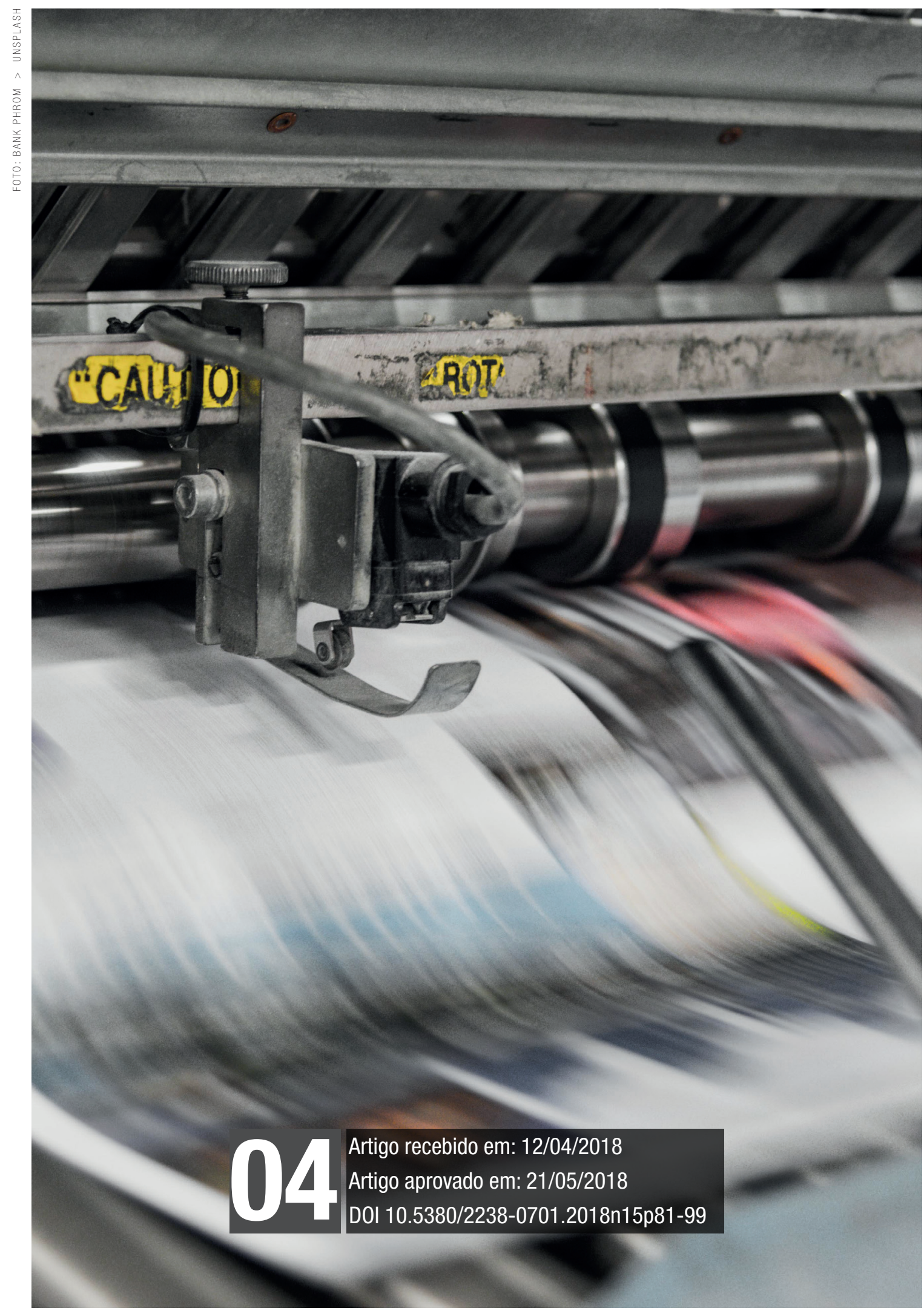


Jornalismo político; Editorial; Impeachment; El País; Dilma Rousseff. 


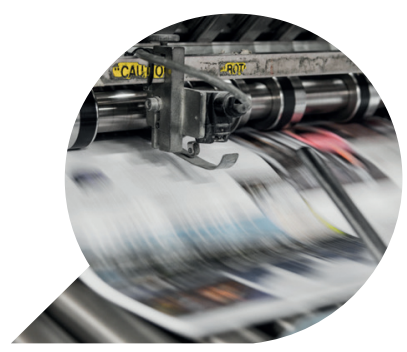

\title{
O impeachment de Dilma Rousseff nos editoriais do jornal El País
}

\author{
La acusación de Dilma Rousseff en los \\ editoriales del diario El País
}

The impeachment of Dilma Rousseff in the editorials of the newspaper El País

RENATO SORDI TOLENTINO DA SILVA ${ }^{1}$

RAFAEL CARDOSO SAMPAIO $^{2}$

Resumo: $\mathrm{O}$ artigo tem como objetivo analisar o posicionamento do jornal El País, em seus editoriais, sobre o impeachment da ex-presidente Dilma Rousseff. Para a investigação, foi constituído um corpus formado por nove editoriais publicados entre $1^{\circ}$ de dezembro de 2015 e 31 de agosto de 2016, período que compreende entre a aceitação da denúncia pela Câmara dos Deputados e o afastamento em definitivo pelo Senado. A metodologia adotada para o desenvolvimento do trabalho foi a Análise de Conteúdo, que foi guiada pelos conceitos de enquadramento e jornalismo cínico. A pesquisa constatou que o El País apresentou a destituição como um processo irregular e um fato essencialmente negativo para o país.

1 Mestrando do Programa de Pós-Graduação em Comunicação da Universidade Federal do Paraná (UFPR).

2 Doutor em Comunicação e Cultura Contemporâneas pela Universidade Federal da Bahia (UFBA), professor adjunto do Curso de Ciências Sociais daUniversidade Federal do Paraná (UFPR). 
Palavras-chave: Jornalismo político; Editorial; Impeachment; El País; Dilma Rousseff.

Resumen: El artículo tiene como objetivo analizar el posicionamiento del diario El País, en sus editoriales, sobre el impeachment de la presidenta Dilma Rousseff. Para la investigación, se constituyó un corpus formado por nueve editoriales publicados entre $1 \mathrm{de}$ diciembre de 2015 y el 31 de agosto de 2016, período que comprende entre la aceptación de la denuncia por la Cámara de Diputados y el alejamiento por el Senado. La metodología adoptada para el desarrollo del trabajo fue el Análisis de Contenido, que fue guiado por los conceptos de encuadramiento y periodismo cínico. La investigación constató que El País presentó la destitución como un proceso irregular y un hecho esencialmente negativo para el país.

Palabras clave: Periodismo político; Editorial; Impeachment; El País; Dilma Rousseff.

Abstract: The article aims to analyze the positioning of the newspaper El Pais, in its editorials, about the impeachment of former president Dilma Rousseff. For the investigation, a corpus was formed consisting of nine editorials published between December 1, 2015 and August 31,2016, period between the acceptance of the denunciation by the Chamber of Deputies and the definitive removal by the Senate. The methodology adopted for the development of the work was Content Analysis, which was guided by the concepts of framing and cynical journalism. The survey found that El Pais presented the dismissal as an irregular process and a fact essentially negative for the country.

Keywords: Political journalism; Editorial; Impeachment; El País; Dilma Rousseff. 


\section{Introdução}

O impeachment da presidente Dilma Rousseff recebeu ampla cobertura da imprensa internacional. Entre dezembro de 2015 e agosto de 2016, período que compreende a aceitação da denúncia oferecida pelos advogados Hélio Bicudo, Janaína Paschoal e Miguel Reale Júnior na Câmara dos Deputados e a votação em definitivo da destituição pelo Senado, o impeachment, bem como seus desdobramentos políticos, econômicos e sociais, foi tema recorrente não apenas da cobertura noticiosa da imprensa estrangeira, mas também de editoriais dos principais jornais do mundo.

Enquanto na seção de notícias o jornal reivindica sua condição de imparcialidade, no texto editorial, ocorre o oposto: a instituição jornalística deixa de lado a premissa da isenção para assumir posições claras a respeito da política, economia, questões sociais e outros assuntos candentes (MONT'ALVERNE; MARQUES, 2015). O editorial pode funcionar também como mediador de temas polêmicos e embates que ocorrem na sociedade, além de operar na tematização do debate, contribuindo para a formação da opinião pública (MORAES, 2007). As opiniões publicadas pelos jornais em seus editoriais revelam os princípios fundamentais defendidos pela organização midiática, são as "linhas mestras que marcam ideologicamente os conteúdos jornalísticos e fundamentam a atividade empresarial de uma publicação" (ARMAÑANZAS e NOCÍ, 1996, p. 171).

A opinião das empresas jornalísticas a respeito do impeachment tem sido objeto de estudo de pesquisadores dos campos da Comunicação e da Ciência Política recentemente. Guazina, Prior e Araújo (2017) constataram diferenças assimiláveis nos editoriais de jornais brasileiros e estrangeiros sobre o tema. Enquanto os periódicos nacionais, em linhas gerais, se ocuparam com a legitimidade do impeachment, refutando a tese de golpe e ressaltando a constitucionalidade do processo, os diários internacionais se mostraram céticos e indicaram que a queda da ex-presidente não ocorreu em razão dos fatos pelos quais ela foi acusada, levantando dúvidas e preocupações com os efeitos do processo. Marques, Mont'alverne e Mitozo (2017) verificaram que a Folha de S. Paulo e O Estado de S. Paulo assumiram, em seus editoriais, a defesa de que o impeachment deveria ocorrer, elencando argumentos para justificar a legitimidade do processo. Por sua vez, Albuquerque e Paula (2017) não se furtam de considerar o impeachment como um golpe de estado parlamentar e a necessidade da pesquisa sobre comunicação política refletir sobre as consequências de um jornalismo que apoiou o processo. 
Nesse sentido, esta análise pretende contribuir ao debate que envolve as relações entre jornalismo opinativo e impeachment, podendo também colaborar para compor o quadro analítico a respeito do posicionamento político dos jornais internacionais a respeito da destituição da ex-presidente brasileira.

Dessa forma, este trabalho se dedica a estudar o posicionamento dos editoriais publicados pelo jornal espanhol El País a respeito do impeachment de Dilma Rousseff. Para o artigo, foram selecionados nove textos opinativos publicados pelo diário europeu entre os dias $1^{\circ}$ de dezembro de 2015 e 31 de agosto de 2016, período em que o processo tramitou formalmente no Congresso, que tratam diretamente do impeachment da ex-presidente.

A coleta dos dados foi realizada a partir do website do El País. A opção por estudar o periódico levou em conta que o El País é considerado um jornal de referência internacional ${ }^{3}$. Também foi um dos veículos de comunicação estrangeiros mais ativos na cobertura do impeachment e que mais se posicionou, em editoriais, a respeito da crise política brasileira. Nota-se que o estudo trata da versão espanhola do diário, fundada em 1976 e sediada em Madri, e não da edição brasileira, que passou a ser publicada na internet em 2013. A metodologia utilizada para a operacionalização da pesquisa foi a Análise de Conteúdo (AC), a partir da formulação proposta por Bauer (2002). No sentido de instrumentalizar a AC, foram elaboradas cinco variáveis: Causas do impeachment; Efeitos do impeachment; Protagonistas da Corrupção; Papel de Dilma na Narrativa e Valência do impeachment. As variáveis serão explicadas posteriormente de forma mais aprofundada.

O trabalho está estruturado da seguinte maneira. Na sequência, é apresentado o desenvolvimento teórico sobre o conceito de jornalismo cínico. A seguir, são apresentados os procedimentos metodológicos utilizados e realizada a análise do corpus. Os resultados evidenciam que o El País não se furtou de fazer duras críticas ao processo de impeachment, inclusive classificando-o como golpe institucional e afirmando que o mesmo não resolveria a situação econômica brasileira, porém também faz críticas generalizantes sobre a corrupção no país. Ao final, busca-se realizar considerações sobre o limite do conceito de jornalismo cínico.

30 El País tem como política editorial dar amplo destaque à seção internacional. Neste quesito, foi um dos primeiros jornais do mundo a dedicar as primeiras páginas às notícias internacionais. Informação disponível em: https://brasil.elpais.com/brasil/2017/02/22/opinion/1487788532_309244. html. Acesso em: 27 de março de 2018. 


\section{Jornalismo cínico}

O jornalismo, como sabemos, viveu inúmeras fases até adquirir a forma contemporânea. Foi, por exemplo, partidário até o século XVIII, quando começou a ser reinventado sobre os conceitos da independência e objetividade. Justamente para se afastar de sua faceta ligado a grupos e partidos, o jornalismo se proclamou como um defensor do interesse público, um cão de guarda do campo político a serviço da população, passando a adotar valores como objetividade e isenção. Isso, entretanto, em diversos casos, levaria o jornalismo a ser excessivamente crítico e negativo na cobertura de fatos e de atores políticos (GOMES, 2004; ALBUQUERQUE, 2012). Nessa toada, o conceito de jornalismo cínico foi desenvolvido por Poletti e Brants (2010) para se referir a práticas jornalísticas cada vez mais presentes nas democracias atuais. Estas práticas resultam em uma cobertura jornalística que prioriza abordagens negativas dos acontecimentos, notícias cada vez menos substanciais, com foco nos indivíduos e nos escândalos, além do uso de manchetes apelativas e focadas no espetáculo. Segundo as autoras, estas rotinas podem ser designadas como "atitudes antipolíticas" dos jornalistas e se manifestam no tom e no estilo dos conteúdos produzidos (POLETTI e BRANTS, 2010).

Para definir o conceito, as autoras citam Kiousis (2002), que por sua vez explica que jornalismo cínico pode ser considerado um "conceito multidimensional, que consiste de muitas características potenciais" (POLETTI e BRANTS, 2010:331, tradução própria). A partir deste entendimento, Poletti e Brants (2010) segmentam a ideia em quatro dimensões: desconfiança (expressa a atitude do jornalista diante do agente político); negatividade (ponto de vista expresso no tom do conteúdo produzido); ironia ou sarcasmo (estilo de apresentação) e escândalo ou orientação ao conflito (foco do conteúdo ou enquadramento).

Por sua vez, segundo Miguel (2008), haveria ao menos três razões principais para a mídia ser, prioritariamente, cínica em relação aos políticos. Inicialmente, estaria a "ideologia profissional", que demanda que o jornalista desconfie das aparências e sempre busque pelo escondido, pelo não dito, por motivos escusos e ocultos. Depois, a especialização profissional dos jornalistas teria incentivado uma cobertura "hiperpolitizada" das práticas políticas, na qual todos os eventos políticos precisariam ser compreendidos como disputas políticas pelo poder. Por último, o foco nos malfeitos, nos erros e nos escândalos seria estratégico, uma 
vez que seriam vistos como mais valorosos como notícias, restando, logo, pouco espaço para uma cobertura mais positiva ou mesmo propositiva da política. Ademais, Miguel (2008) alerta que o jornalismo excessivamente cínico tende a ser um considerado um dos principais fatores para a explicação da espiral do cinismo. De forma breve, a cobertura excessivamente negativa dos políticos pela imprensa levaria o público a confiar gradativamente menos em seus representantes e instituições políticas, fomentando uma atitude cínica em relação aos mesmos. Por sua vez, o efeito seria uma espiral, pois também os políticos veriam que não há, via de regra, como conseguir uma cobertura política mais positiva, então passariam a não se importar com o público, comportando-se também de forma mais cínica.

Reconhecemos que tais conceitos não podem ser aplicados de forma inequívoca. Há uma literatura que busca justamente reconhecer as conexões entre comunicação e democracia (GOMES e MAIA, 2008; MAIA, 2008; HABERMAS, 2008; ), apontando uma série de formas pelas quais a sociedade civil ou mesmo o estado podem conseguir propor (ou mesmo forçar) agendas mais positivas para questões políticas de diferentes naturezas. Ademais, outros autores também já buscaram demonstrar empírica e teoricamente os limites de teorias similares a respeito dos supostos malefícios dos media ${ }^{4}$. Em especial, Schudson (2008) defende que um jornalismo baseado em eventos, em uma cobertura negativa da política; ou seja, um jornalismo não amável, seja justamente o que as democracias precisam. De outra forma, seriam as democracias a perderem por não terem essa instituição para criticar, cobrar e investigar os poderes tradicionais. Essa faceta detestável ou não-amável do jornalismo que teria um efeito maior de impedir os agentes políticos de cometerem (ainda mais) desvios.

Diante do conceito de jornalismo cínico e da possibilidade de o mesmo gerar essa espiral do cinismo, mas cientes da sua limitação, apresentamos nossa análise exploratória do caso do El País.

\section{Procedimentos metodológicos}

A coleta do corpus foi realizada a partir do website do El País no dia 27 de março de 2018. Para operacionalizar o inventário, inicialmente foi localizada a tag que identifica os textos editoriais. A partir da tag

4 Argumentos seminais sobre os limites de tais teorias sobre os supostos malefícios podem ser vistos em Gomes (2008) e Maia (2008). 
foi acessada a página onde são publicados os editoriais veiculados pelo diário, que são apresentados em ordem cronológica decrescente. Em seguida, foram identificadas as publicações com data de 31 de agosto de 2016. A partir daí, foram acessados todos os editoriais publicados pelo El País, de forma individual e retroativa, entre 31 de agosto de 2016 e $1^{\circ}$ de dezembro de 2015. A cada acesso foram realizadas buscas, no navegador, pelos termos "Dilma Rousseff" e "impeachment". A partir deste procedimento foram identificados e elencados nove textos que tratam diretamente da destituição da ex-presidente, conforme Tabela 1. Na sequencia, foram gerados arquivos no formato PDF para posterior manipulação e análise do corpus.

Tabela 1: Lista de editoriais publicados pelo El País sobre o impeachment

\begin{tabular}{c|c}
\hline Data da publicação & Título \\
\hline $01 / 12 / 2015$ & Brasil debe reaccionar \\
\hline $03 / 12 / 2015$ & Proceso arriesgado en Brasil \\
\hline $04 / 03 / 2016$ & Otro golpe a Brasil \\
\hline $14 / 03 / 2016$ & Brasil, empantanado \\
\hline $17 / 03 / 2016$ & Alta tensión en Brasil \\
\hline $30 / 03 / 2016$ & La soledad de Rousseff \\
\hline $18 / 04 / 2016$ & Brasil ante el abismo \\
\hline $10 / 05 / 2016$ & Un proceso irregular \\
\hline $31 / 08 / 2016$ & Golpe bajo en Brasil \\
\hline
\end{tabular}

Fonte: Dados da pesquisa

A Análise de Conteúdo foi realizada a partir da proposta de Bauer (2002). No sentido de operacionalizar a AC, foram formuladas cinco variáveis: Causas do impeachment; Efeitos do impeachment; Protagonistas da Corrupção; Papel de Dilma na Narrativa e Valência do impeachment. Para cada variável, foram elaboradas categorias relacionadas diretamente com o objeto da pesquisa. As variáveis e categorias foram construídas com base no Livro de Códigos - Enquadramento Multimodal - Impeachment do Grupo de Pesquisa Comunicação e Participação Política da Universidade Federal do Paraná ${ }^{5}$ e na cobertura negativa que poderia

5 O Livro de Códigos - Enquadramento Multimodal - Impeachment do Grupo de Pesquisa Comunicação e Participação Política da UFPR está disponível em: https://bdc.c3sl.ufpr.br/handle/123456789/25. Para aplicação completa, ver Rizzotto, Prudencio, Sampaio (2017). Acesso em: 
ser proposta por um jornalismo cínico e nas saliências que a cobertura pode dar com base na teoria do enquadramento (cf. Rizzotto, Prudencio, Sampaio, 2017).

A variável Causas do impeachment, que analisa os motivos elencados pelo jornal para o afastamento, foi dividida em sete categorias: 1) Corrupção - o texto identifica casos de corrupção no governo Dilma ou a Operação Lava Jato como motivadores do impeachment; 2) Crise econômica - aponta a recessão econômica como causadora do afastamento; 3) Crise política - indica a perda de poder da ex-presidente por conta da degeneração da base aliada no Congresso como motivador do impeachment; 4) Manobra política da oposição - identifica como responsável pela destituição o então presidente da Câmara dos Deputados, Eduardo Cunha, e partidos da oposição; 5) Manobra política de Michel Temer pelo poder - assinala que o impeachment foi causado pelo vice-presidente com a intenção de assumir o poder; 6) Pedaladas fiscais - atribui as operações orçamentárias realizadas por Dilma como motivadoras do afastamento; 7) Pressão popular - imputa às manifestações de rua como incentivadoras do impeachment.

Por sua vez, a variável Efeitos analisa as consequências apresentadas pelo jornal madrilenho para o impeachment e foi segmentada em oito categorias: 1) Corrupção vai acabar - indica como efeito do afastamento a diminuição da corrupção no Brasil; 2) Corrupção não vai acabar aponta que o impeachment não representa o fim da corrupção no país; 3) Compromete o futuro da democracia - identifica que a destituição prejudica a democracia brasileira; 4) Ajuda a resolver a crise econômica - imputa o afastamento da ex-presidente à retomada do crescimento econômico; 5) Não ajuda a resolver a crise econômica - identifica que o impeachment não é um fator determinante para a retomada do crescimento econômico; 6) Aumenta a divisão política - assinala que o impeachment amplifica a divisão política na sociedade; 7) Prejudica as instituições democráticas - o editorial aponta que o afastamento prejudica as instituições democráticas; 8) Agrava a crise política - torna a crise política ainda mais crítica.

Como o jornal qualificou os personagens envolvidos no impeachment, no que tange ao tema da corrupção, foi estudado na variável Protagonistas da Corrupção. A variável foi segmentada em oito categorias: 1) Dilma é corrupta - identifica a ex-presidente como responsável direta por casos de corrupção; 2) Dilma é inocente - aponta que não há pro- 
vas do envolvimento pessoal de Dilma em casos de corrupção; 3) Lula é corrupto - imputa ao ex-presidente envolvimento pessoal em casos de corrupção; 4) Lula é inocente - identifica que não há evidências de envolvimento pessoal de Lula nos casos de corrupção; 5) PT é corrupto - implica diretamente o partido em escândalos de corrupção; 6) PT é inocente - o editorial indica que o partido não se envolveu em casos de corrupção; 7) Políticos articuladores do impeachment são corruptos - os políticos que defenderam o impeachment são acusados de envolvimento em casos de corrupção; 8) A corrupção é generalizada na classe política.

A variável Papel de Dilma na Narrativa considera quatro categorias: 1) Vítima - o texto se refere à ex-presidente como alguém que está sendo prejudicada e injustiçada; 2) Heroína - o texto enaltece qualidades nobres de Dilma, qualificando a ex-presidente como alguém que luta pela justiça e/ou contra um vilão; 3) Vilã - identifica Dilma como responsável por causar problemas específicos a outras pessoas ou grupos, ou ainda que prejudica e causa danos à sociedade; 4) Não se posiciona.

Por fim, a variável Valência do impeachment foi categorizada da seguinte forma: 1) Negativo - o texto identifica o impeachment como negativo para o país; 2) Positivo - editorial elenca argumentos para defender que o afastamento é positivo para o Brasil; 3) Neutro; 4) Não se posiciona.

\section{Resultados da análise dos editoriais}

Inicialmente, é possível destacar que o El País apresentou a recessão econômica como o principal fator causador do impeachment, conforme a tabela 2. Foram encontradas sete referências ao tema nos editoriais, totalizando $32 \%$ das respostas inventariadas. Os temas relacionados à corrupção, com seis referências identificadas, foram outro tópico que recebeu atenção do jornal espanhol, como um indutor do processo de destituição. Em suma, do total de 22 respostas encontradas, 13 relacionam as causas do impeachment à crise econômica ou corrupção. $\mathrm{O}$ diário identificou a destituição como uma manobra política da oposição em quatro oportunidades; e motivado pela crise política em três ocasiões. Curiosamente, as chamadas pedaladas fiscais, justificativa que fundamentou a queixa-crime formulada por advogados, que deu início ao processo de afastamento, não foram mencionadas em nenhum momento pelos editorialistas do El País. 
A Tabela 3 aponta que o diário espanhol demonstrou preocupação com o futuro da democracia brasileira. Do total de 11 ocorrências, o diário afirmou que a destituição pode comprometer o futuro da democracia três vezes. O El País também apontou que a destituição poderia ter efeito no aumento da divisão política da sociedade, na deterioração das instituições democráticas e também no agravamento da crise política. Para cada uma destas categorias, foram identificadas duas incidências positivas. Neste sentido, o diário publicou: "o impeachment deixa um país dividido politicamente e imerso na pior crise econômica de sua história”. O jornal destacou ainda que a destituição não teria efeito na diminuição da corrupção e não ajudaria a solucionar a crise econômica. Por outro lado, nenhuma incidência foi identificada no sentido de que o impeachment teria como efeito o fim da corrupção e a solução da recessão econômica brasileira.

Tabela 2: Causas do impeachment nos editoriais do El País

\begin{tabular}{l|c|c|c}
\hline \multicolumn{1}{c|}{ Causas do impeachment } & $\begin{array}{c}\text { Frequência } \\
\text { total }\end{array}$ & $\begin{array}{c}\text { \% Frequência } \\
\text { total }\end{array}$ & $\begin{array}{c}\text { \% Frequência } \\
\text { relativa }\end{array}$ \\
\hline Crise econômica & 7 & $78 \%$ & $32 \%$ \\
\hline Corrupção & 6 & $67 \%$ & $27 \%$ \\
\hline Manobra política da oposição & 4 & $44 \%$ & $18 \%$ \\
\hline Crise política & 3 & $33 \%$ & $14 \%$ \\
\hline Pressão popular & 1 & $11 \%$ & $4,5 \%$ \\
\hline $\begin{array}{l}\text { Manobra de Temer para assumir o } \\
\text { poder }\end{array}$ & 1 & $11 \%$ & $4,5 \%$ \\
\hline Pedaladas fiscais & 0 & $0 \%$ & $0 \%$ \\
\hline \multicolumn{1}{c|}{ Total } & $\mathbf{2 2}$ & - & $100 \%$ \\
\hline
\end{tabular}

Fonte: Dados da pesquisa 
Tabela 3: Efeitos do impeachment nos editoriais do El País

\begin{tabular}{l|c|c|c}
\hline \multicolumn{1}{c|}{ Efeitos do impeachment } & $\begin{array}{c}\text { Frequência } \\
\text { total }\end{array}$ & $\begin{array}{c}\text { \% Frequência } \\
\text { total }\end{array}$ & $\begin{array}{c}\text { \% Frequência } \\
\text { relativa }\end{array}$ \\
\hline $\begin{array}{l}\text { Compromete o futuro da demo- } \\
\text { cracia }\end{array}$ & 3 & $33 \%$ & $28 \%$ \\
\hline Aumenta a divisão política & 2 & $22 \%$ & $18 \%$ \\
\hline $\begin{array}{l}\text { Prejudica as instituições demo- } \\
\text { cráticas }\end{array}$ & 2 & $22 \%$ & $18 \%$ \\
\hline Agrava a crise política & 2 & $22 \%$ & $18 \%$ \\
\hline Corrupção não vai acabar & 1 & $11 \%$ & $9 \%$ \\
\hline $\begin{array}{l}\text { Não ajuda a resolver a crise eco- } \\
\text { nômica }\end{array}$ & 1 & $11 \%$ & $9 \%$ \\
\hline Corrupção vai acabar & 0 & $0 \%$ & $0 \%$ \\
\hline $\begin{array}{l}\text { Ajuda a resolver a crise econô- } \\
\text { mica }\end{array}$ & 11 & $0 \%$ & $0 \%$ \\
\hline \multicolumn{1}{c}{ Total } & - & $100 \%$ \\
\hline
\end{tabular}

Fonte: Dados da pesquisa

O estudo também investigou como a corrupção foi abordada nos editoriais, mais especificamente como foram qualificados os personagens políticos que protagonizaram o impeachment em relação ao tema, como pode ser observado na Tabela 4 . Do total de 14 respostas, cinco indicam que o El País considerou, textualmente, que não havia contra a ex-presidente provas de participação pessoal nos escândalos de corrupção de seu governo ao tempo que, em nenhuma ocasião, foi vinculado à ex-presidente o rótulo de corrupta.

Interessante constatar que, se o jornal isentou Dilma do envolvimento em escândalos de desvios de recursos públicos e outros malfeitos, o mesmo não ocorreu em relação ao ex-presidente Lula e ao Partido dos Trabalhadores. Lula foi qualificado como corrupto em três oportunidades, enquanto o PT em duas. Neste sentido, o jornal afirmou em seus editoriais: "foi impossível encontrar alguma prova de implicação de Dilma no escândalo da Lava Jato" e "as sucessivas investigações não puderam demonstrar a participação da presidente na corrupção de seu partido".

Por outro lado, sobre Lula e o PT, o jornal estampou: "é destruidora para a imagem do primeiro sindicalista que chegou à presidência a 
acusação de que duas empreiteiras pagaram um apartamento na praia e uma casa de campo" e "o escândalo de corrupção na Petrobras afetou em cheio o Partido dos Trabalhadores chegando inclusive ao ex-presidente Lula”. O El País apontou ainda que a corrupção é generalizada na classe política brasileira em três ocasiões, e especificamente que os políticos que articularam o impeachment são corruptos em duas, conforme Tabela 4.

Tabela 4: Protagonistas da Corrupção nos editoriais do El País

\begin{tabular}{l|c|c|c}
\hline Protagonistas da Corrupção & Frequência total & $\begin{array}{c}\% \text { Frequência } \\
\text { total }\end{array}$ & $\begin{array}{c}\% \text { Frequência } \\
\text { relativa }\end{array}$ \\
\hline Dilma é inocente & 5 & $56 \%$ & $36,2 \%$ \\
\hline Lula é corrupto & 3 & $33 \%$ & $21,2 \%$ \\
\hline $\begin{array}{l}\text { Corrupção é generalizada na } \\
\text { classe política }\end{array}$ & 3 & $33 \%$ & $14,2 \%$ \\
\hline PT é corrupto & 2 & $22 \%$ & $14,2 \%$ \\
\hline $\begin{array}{l}\text { Políticos articuladores } \\
\text { do impeachment são } \\
\text { corruptos }\end{array}$ & 2 & $22 \%$ & $14,2 \%$ \\
\hline Dilma é corrupta & 0 & $0 \%$ & $0 \%$ \\
\hline Lula é inocente & 0 & $0 \%$ & $0 \%$ \\
\hline PT é inocente & 0 & $0 \%$ & $0 \%$ \\
\hline \multicolumn{1}{c|}{ Total } & 14 & - & $100 \%$ \\
\hline
\end{tabular}

Fonte: Dados da pesquisa

Tabela 5: O Papel de Dilma na Narrativa do impeachment nos editoriais do El País

\begin{tabular}{|c|c|c|}
\hline Papel de Dilma na Narrativa & Frequência total & \% Frequência total/relativa \\
\hline Vítima & 6 & $67 \%$ \\
\hline Não se posiciona & 2 & $22 \%$ \\
\hline Vilã & 1 & $11 \%$ \\
\hline Heroína & 0 & $0 \%$ \\
\hline Total & 9 & $100 \%$ \\
\hline
\end{tabular}

Fonte: Dados da pesquisa 
A Tabela 5 revela que o El País atribuiu a Dilma o papel de vítima, quando se refere à ex-presidente como alguém que está sendo prejudicada e/ou injustiçada, em seis editoriais, de um total de nove. O jornal descreve Dilma em "agonia" e afirma que a ex-presidente deixa o cargo "previsivelmente derrotada e humilhada pela porta de trás da história". Revela também uma Dilma injustiçada em razão do "processo irregular de destituição" e do "abandono de seus sócios de governo". A ex-presidente surge como vilã em apenas uma oportunidade, na ocasião da nomeação de Lula para a chefia da Casa Civil em março de 2016.

Ao verificar a valência adotada pelo jornal em relação ao impeachment, é possível verificar que o El País considerou o processo de afastamento um fato negativo para o país. Neste sentido, o jornal qualificou repetidas vezes o impeachment como "golpe constitucional", "processo irregular" ou ainda um "golpe baixo para o funcionamento institucional" no Brasil, ressaltando o "caos institucional" e as "incertezas" acarretadas pelo processo. Em nenhuma oportunidade, o periódico apontou impeachment como uma ocasião positiva, conforme Tabela 6.

Tabela 6: Valência do impeachment nos editoriais do El País

\begin{tabular}{l|c|c}
\hline \multicolumn{1}{c|}{ Valência do impeachment } & Frequência total & \% Frequência total/relativa \\
\hline Negativa & 6 & $67 \%$ \\
\hline Não se posiciona & 3 & $33 \%$ \\
\hline Positiva & 0 & $0 \%$ \\
\hline Neutra & 0 & $\mathbf{0} \%$ \\
\hline Total & $\mathbf{9}$ & $\mathbf{1 0 0 \%}$ \\
\hline
\end{tabular}

Fonte: Dados da pesquisa

\section{Resultados e considerações finais}

A utilização da AC nos editoriais do El País revela que o diário espanhol tratou a destituição da presidente como um golpe institucional e apresentou, reiteradamente, o processo como um fato essencialmente negativo para o país. A investigação revela que, de acordo com o jornal, o impeachment foi motivado, essencialmente, pela recessão econômica e pelas denúncias de corrupção que envolveram o governo Dilma, 
o ex-presidente Lula e o PT. Todavia, também o enquadrou como uma manobra política da oposição diante crise política instaurada no país.

Chama a atenção que o El País optou por destacar as consequências essencialmente negativas do impeachment, como a corrosão da democracia, o aumento da divisão política, a degradação das instituições e a piora na crise política. Ao centrar a análise na ex-presidente, é possível verificar que o El País considera Dilma idônea, que não se envolveu pessoalmente em casos de corrupção que ocorreram em seu governo e partido. O jornal também aponta que Dilma foi vítima de um processo de deposição irregular e injusto.

Em uma sentença, podemos afirmar que investigação apurou os seguintes resultados: os editoriais do El País revelam que o impeachment foi causado pela crise econômica, denúncias de corrupção e consiste em uma manobra política da oposição, com efeitos na corrosão da democracia brasileira e aumento da divisão política na sociedade; Dilma foi vítima de um processo irregular e não pode ser acusada de corrupção, embora Lula e o PT, sim.

Os resultados apurados coincidem com as respostas encontradas por Guazina, Prior e Araújo (2017). Assim como os jornais internacionais analisados pelos pesquisadores, o El País se mostrou cético em relação ao impeachment, apontando que a destituição não ocorreu necessariamente em razão dos fatos pelos quais ela foi acusada, levantando questionamentos e preocupações sobre os efeitos do processo. $\mathrm{O}$ posicionamento do El País sobre o impeachment era esperado e está de acordo com as posições ideológicas do diário ${ }^{6}$, considerando que os textos editoriais revelam as linhas ideológicas das organizações de comunicação (ARMAÑANZAS e NOCÍ, 1996).

Em uma análise preliminar, é possível afirmar haver, nos editoriais analisados, algum grau de jornalismo cínico proposto por Poletti e Brants (2010) em virtude do realce das opiniões essencialmente negativas e também do uso de títulos chamativos, como "Golpe baixo no Brasil" e "Alta tensão no Brasil", além dos destaques sobre corrupção generalizada e afins. Não obstante, quando comparamos nossos resultados à análise de editoriais (MARQUES, MONTALVERNE, MITOZO, 2017) e de notícias (RIZZOTTO, PRUDENCIO, SAMPAIO, 2017) de jornais brasileiros sobre o impeachment, percebe-se que o

60 El País se apresenta como um jornal comprometido com a defesa da democracia e das minorias marginalizadas. Informação disponível em: https://brasil.elpais.com/brasil/2017/02/22/opinion/1487788532_309244.html. Acesso: 27 de março de 2018. 
El País parece ter sido mais capaz de politizar de fato questões pertinentes envolvidas no processo, incluindo a possibilidade de se tratar efetivamente de um golpe parlamentar. Em outras palavras, mesmo optando por um jornalismo mais crítico, mais cínico, o diário foi apto em tentar expandir e compreender impactos políticos, econômicos e democráticos que tal decisão traria.

Se o jornalismo brasileiro optou frequentemente por normalizar a questão, tratando o impeachment como um fato político corriqueiro, como definido por Rizzotto et al (2017), o El País não se furtou de pôr o dedo na ferida e denotar a ruptura democrática ocasionada pelo impeachment, inclusive classificando-o como golpe institucional e afirmando que o mesmo dificilmente teria um efeito positivo para a crise econômica. Críticas que foram praticamente inexistentes no caso do jornalismo brasileiro. Como definido por Schudson (2008), apesar dos possíveis efeitos negativos, as democracias precisam de imprensas "não amáveis", que estejam ali ressaltando mal feitos e ajudando a manter agentes e instituições políticas com medo de serem pegos em transgressões. Ademais, ao contrário do que esperávamos, o jornalismo cínico, no caso do El Pais, também não se manifestou numa lógica colonialista, reduzindo o Brasil apenas a um desorganizado país de terceiro mundo. Em oposição a isso, inclusive ressaltou a importância do Brasil como player mundial em termos econômicos e políticos, o que apenas reforçou o desastre que poderia ser gerado pelo impeachment. Uma contradição, entretanto, foi comprar integralmente o discurso do processo jurídico contra o ex-presidente Lula e a própria visão, geralmente simplória, de que todos corruptos merecem igual tratamento, igualando crimes ou mesmo acusações de diferentes naturezas.

Em resumo, a ideia de um jornalismo "hiperpolitizado", "adversário" ou "cínico" é certamente útil para operacionalização conceitual de análises de conteúdo da cobertura midiática, porém não deve ser um fim em si mesmo. O jornalismo pode ser cínico em relação aos políticos, mas contribuir com o debate público, manter políticos sob vigilância e desvelar mal feitos e transgressões de diferentes naturezas. Por outro lado, quando seu objetivo é ser exclusivamente oposição, isso pode ser de fato problemático. Ou ainda, quando não assume uma posição em casos extremos, como foi o caso de impeachment, seja por seu modus operandi (RIZZOTTO, PRUDENCIO, SAMPAIO, 2017) seja por interesses escusos (ALBUQUERQUE, PAULA, 2017). 
Como, atualmente, o acesso a editoriais e opiniões de grandes periódicos do mundo se tornou mais fácil, rotineiro e como, frequentemente, são alvos de ampla discussão no país (seja por repercussão da própria imprensa tradicional seja pela repercussão em redes sociais online), futuras pesquisas deveriam se voltar para análises internacionais e comparadas desses artigos de opinião (cf. realizado por GUAZINA, PRIOR, ARAÚJO, 2017). A análise aqui proposta é uma primeira aproximação ao fenômeno e deve ser aprofundada e expandida em estudos posteriores.

\section{REFERÊNCIAS}

ALBUQUERQUE, A. O paralelismo político em questão. Revista Compolítica, v. 2, n. 1, p. 5-28, 2012.

ALBUQUERQUE, A.; PAULA, C. A. . Accountability contra democracia: a comunicação política depois do golpe. In: VII Encontro da Compolítica, 2017, Porto Alegre. Anais..., 2017. p. 1-29.

ARMAÑANZAS, E.; NOCÍ, J.D. Periodismo y argumentación. Géneros de opinión. Universidad del Pais Vasco, 1996.

BAUER, M. W. Análise de conteúdo clássica: uma revisão. In: BAUER, M. W.; GASKELL, G. (Org.). Pesquisa qualitativa com texto, imagem e som: um manual prático. Petrópolis: Vozes, 2002. p. 189-217.

GOMES, W. Transformações da política na era da comunicação de massa. Editora Paulus, 2004.

GOMES, W.; MAIA, R. Comunicação e democracia: problemas e perspectivas. São Paulo: Paulus, 2008.

GOMES, W. Capital social, democracia e televisão em Robert Putnam.. In: GOMES, W.; MAIA, R.C.M. (Org.). Comunicação e Democracia: Problemas \& Perspectivas.. São Paulo: Paulus, 2008, p. 221-274.

GUAZINA, L. S.; PRIOR, H.; ARAÚJO, B. Enquadramentos de uma crise: o impeachment de Dilma Rousseff em editoriais nacionais e internacionais. In: COMPOLÍTICA, n. VII, 2017, Porto Alegre. Anais. 
HABERMAS, Jürgen. Comunicação política na sociedade mediática: o impacto da teoria normativa na pesquisa empírica. Líbero, n. 21, p. 9-21, 2016.

MAIA, R. Mídia e deliberação. Rio de janeiro, FGV Editora, 2008.

MONT'ALVERNE, C.; MARQUES, F. P. J. A. A opinião da empresa no Jornalismo brasileiro: Um estudo sobre a função e a influência política dos editoriais. Estudos em Jornalismo e Mídia (UFSC), v. 12, p. 121-137, 2015.

MARQUES, F. P. J.; MONTALVERNE C.; MITOZO I. O impeachment de Dilma Rousseff nos editoriais de Folha e Estadão: um estudo quanti-qualitativo sobre o posicionamento político dos jornais. In: COMPÓS, 2017, São Paulo. Anais.

MIGUEL, L. F. A mídia e o declínio da confiança na política. Sociologias, v. 10, n. 19, 2008 .

MORAES, C. H. Parcialidade alardeada: notas sobre a importância da opinião no jornalismo. In: IX Colóquio Internacional sobre a Escola Latino-Americana de Comunicação, 2007, Pelotas - RS. XI Celacom, 2007. Anais.

POLETTI M., BRANTS, B. Between partisanship and cynicism: Italian journalism in a state of flux, SAGE Publications, 2010, p.331-332.

RIZZOTTO, C.; PRUDENCIO, K.; SAMPAIO, R. Tudo Normal: a despolitização no enquadramento multimodal da cobertura do impeachment de Dilma Rousseff. Comunicação \& Sociedade, v. 39, n. 3, p. 111-130, 2017.

SCHUDSON, Michael. Why democracies need an unlovable press. Polity, 2008. 